\title{
Revisão sobre a toxicidade e impactos ambientais relacionados à vinhaça, efluente da indústria sucroalcooleira
}

\section{Review of the toxicity and environmental impacts related to vinasse, a sugarcane industry effluent}

\author{
1 Felipe de Aquino Lima \\ 1 Antônio Carvalho dos Santos Junior \\ 1 Luidi Castro Martins \\ 2 Boutros Sarrouh \\ 3 Renata Carolina Zanetti Lofrano renataczlofrano@ufsj.edu.br
}

\footnotetext{
1 Discente do Curso de Engenharia Química pela Universidade Federal de São João del Rei - Campus Alto Paraopeba (UFSJ/CAP).

2 Professor Doutor do Departamento de Química, Biotecnologia e Engenharia de Bioprocessos da Universidade Federal de São João del Rei - Campus Alto Paraopeba (DQBIO/UFSJ/CAP).

3 Professora Doutora do Departamento de Engenharia Química e Estatística da Universidade Federal de São João del Rei Campus Alto Paraopeba (DEQUE/UFSJ/CAP).
}

\section{Resumo}

O Brasil é um dos maiores produtores mundiais de etanol proveniente de cana-de-açúcar. No processo de produção do biocombustível etanol vários resíduos são gerados, dentre eles destaca-se a vinhaça como o mais preocupante, devido as suas características físico-químicas e grande volume gerado. Este efluente é caracterizado altos teores de matéria orgânica, apresentando elevada demanda bioquímica de oxigênio (DBO), pH ácido e a presença de elementos como potássio e enxofre. Tais propriedades conferem a vinhaça um grande poder como poluidor ambiental. Estudos demonstram a contaminação de águas, solos, flora e fauna de mananciais. Considerando-se que o etanol é produzido empregando-se diferentes matérias primas, em inúmeros países, é possível concluir que estamos diante de um problema mundial bastante relevante, relacionado aos usos, armazenamento e descarte desse efluente. Essa revisão apresenta detalhadamente a origem, as propriedades e os impactos ambientais relacionados à vinhaça.

\section{Palavras-chave}

Vinhaça; efluente; indústria sucroalcoleira; impactos ambientais.

\begin{abstract}
Brazil is one of the largest producers of ethanol from sugarcane. In the biofuel ethanol production process various wastes are generated, among which stands out the vinasse as the most worrying, due to its physical and chemical characteristics and large volume generated. This effluent is characterized high organic matter content, with high biochemical oxygen demand (BOD), acid $\mathrm{pH}$ and the presence of elements such as potassium and sulfur. These properties give vinasse great power as an environmental polluter. Studies show the contamination of water, soil, flora and fauna of springs. Considering that ethanol is produced using different raw materials, in many countries, it is possible to conclude that we are facing a very important global problem, related to the use, storage and disposal of the effluent. This review presents in detail the origin, properties and environmental impacts related to stillage.
\end{abstract}

\section{Keywords}

Vinasse; effluent; sugarcane industry; environmental impacts.

\section{Como você deve citar?}

LOFRANO, Renata Carolina Zanetti et al. Revisão sobre a toxicidade e impactos ambientais relacionados à vinhaça, efluente da indústria sucroalcooleira. Cadernos UniFOA, Volta Redonda, n. 32, p. 27-34, dez., 2016. 


\section{INTRODUÇÃO}

O Brasil é, atualmente, um dos maiores produtores mundiais de cana de açúcar, e um dos maiores exportadores de açúcar. Os números deste sistema agroindustrial estão, geralmente, na casa das centenas de milhões de toneladas. De acordo com dados da Companhia Nacional de Abastecimento (CONAB, 2015) estima-se que a safra brasileira de 2015/2016 deverá atingir um montante de 658,7 milhões de toneladas de cana-de-açúcar e em relação à produção de etanol foi estimado um aumento de 1,9\%, o que equivale a 29,21 bilhões de litros de etanol na safra desse ano. Considerando-se que para cada litro de etanol produzido são gerados simultaneamente, aproximadamente 15 litros de vinhaça, calcula-se que 438,15 bilhões de litros desse efluente serão gerados.

A vinhaça, dependendo da região do país é nomeada também como vinhoto, caldo ou "garapão" é proveniente do processo fermentativo empregado na produção do biocombustível etanol. Além dela, outros resíduos, como o bagaço, palha, torta de filtro e cinzas de caldeira também são gerados. Entretanto, a vinhaça é o que recebe a maior atenção devido às suas propriedades físico-químicas e por se tratar de um resíduo altamente poluidor (LAIME, 2011; ROCHA et. al., 2012). Considerando-se que o Brasil é o segundo produtor mundial de etanol, atrás apenas dos EUA, e juntamente com a produção de vários outros países, o volume de vinhaça produzido é muito elevado. Dessa forma, estamos diante de um contexto nacional e mundial bastante preocupante quanto aos usos e descarte desse efluente e estudos voltados à obtenção de métodos eficientes e baratos, que permitam agregar valor a esse resíduo são de grande valia tanto nacional quanto mundialmente. Assim, a presente revisão tornará possível compreender as origens, as propriedades e os impactos ambientais relacionados à vinhaça.

\section{PROPRIEDADES FÍSICO-QUÍMICAS}

Qualquer tipo de líquido capaz de sofrer fermentação é denominado mosto (Figura 1). No processo de produção do etanol três tipos de mostos podem ser utilizados: caldo de cana puro, melaço ou mistura de caldo de cana/melaço. Esses mostos sofrem fermentação por meio de leveduras, originando uma solução alcoólica denominada vinho. A destilação dessa solução gera a vinhaça como subproduto. As propriedades físico-químicas da vinhaça irão depender do tipo de mosto utilizado no processo. Por exemplo, a vinhaça proveniente de mosto de caldo de cana puro apresenta-se mais diluída, se comparada à que é oriunda somente de mosto de melaço. A matéria prima utilizada promove alterações nas propriedades físico-químicas da vinhaça. Além disso, outros fatores como tipo e maturação da cana utilizada, método de fermentação adotado, levedura usada e técnica de destilação empregada, também influenciam na composição final da vinhaça (SILVA, 2007; ROCHA et. al., 2012). 
Figura 1 - Fluxograma processo de produção de etanol (Adaptado de ANDRADE, 2009).

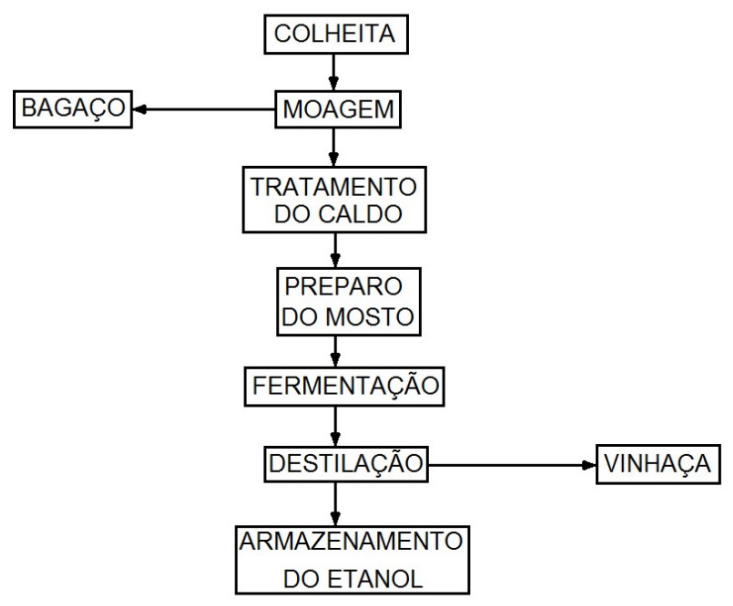

Fonte: dos autores.

A vinhaça apresenta uma coloração parda, que em contato com o ar, sofre oxidação. A putrefação da matéria orgânica presente em sua composição promove um aumento em seu odor desagradável e na sua turbidez. Em geral, ela é uma mistura composta por $93 \%$ de água e $7 \%$ de sólidos. Dentre esses sólidos, aproximadamente, $75 \%$ correspondem a compostos orgânicos e biodegradáveis e $25 \%$ a compostos minerais (LUDOVICE, 1997). A degradação térmica de açúcares redutores e aminocompostos são os principais responsáveis pela coloração escura desse efluente (KANNAN, 2006). Mohana et. al. (2006) em um estudo empregando-se microrganismos capazes de descolorir e degradar anaerobicamente tal mistura, demonstrou que a formação de melanoidinas e compostos polifenólicos, também contribuem para essa coloração. Segundo Chandra et. al. (2008) as melanoidinas são formadas pela reação de Maillard entre aminoácidos e açúcares. Apresentam propriedades antioxidantes que às tornam recalcitrantes à biodegradação.

Não há muitos relatos, na literatura, que especifiquem a composição da vinhaça em termos de compostos orgânicos. Há um consenso geral, como apontam Rocha et. al. (2012) e Seixas et. al. (2016), que grande parte dessa matéria orgânica é constituída por ácidos orgânicos, o que pode contribuir para o baixo pH desse efluente. Glicerol, ácido lático, etanol, ácido acético, frutose, glicose, sacarose, galactose, acetatos, oxalatos e citratos são os compostos orgânicos encontrados em maiores proporções (DOWD et. al., 1994; BENKE et. al., 1998; DECLOUX; BORIES, 2012; PARNAUDEAU et. al., 2008; DOELSCH et. al., 2009 apud SILVA, 2012). Já em relação aos compostos inorgânicos, a composição da vinhaça é mais conhecida, uma vez que a mesma tem seu principal uso na fertirrigação, onde esses componentes atuam como micro e macronutrientes. Entre os compostos inorgânicos, os encontrados em maior proporção são potássio, enxofre, cálcio, nitrogênio, fósforo e magnésio (MUTTON et. al., 2010). Entretanto, verifica-se que os valores de concentrações obtidos por BARROS e BRITO tanto para os componentes inorgânicos quanto para a matéria orgânica são bastante semelhantes, enquanto que os valores citados por Rocha são bastante discrepantes dos demais autores para ambos os tipos de componentes, como pode ser observado na Tabela 1, que apresenta uma comparação entre as concentrações dos componentes inorgânicos e quantidade de matéria orgânica (DQO e DBO) na vinhaça, obtidos a partir de estudos de diferentes autores. 
Tabela 1 - Comparação entre as concentrações dos compostos inorgânicos e da matéria orgânica presentes na vinhaça segundo diferentes autores.

\begin{tabular}{|c|c|c|c|c|c|c|c|c|}
\hline \multirow[t]{2}{*}{ Autores } & \multicolumn{5}{|c|}{ Concentração dos componentes inorgânicos $\left(\mathrm{mg} \mathrm{L}^{-1}\right)$} & \multicolumn{3}{|c|}{$\begin{array}{l}\text { Quantidade de matéria orgânica } \\
\qquad\left(\mathrm{mg} \cdot \mathrm{L}^{-1}\right)\end{array}$} \\
\hline & K & $\mathbf{P}$ & $\mathrm{Ca}$ & $\mathrm{Na}$ & Mg & $\mathbf{N}$ & DQO & DBO \\
\hline BARROS et al. (2010) & 1392,00 & 175,00 & 728,00 & 110,00 & 29,00 & - & 48860,00 & 21275,00 \\
\hline BRITO et al. (2005) & 1318,00 & - & 728,00 & 292,00 & 112,00 & - & 48860,00 & 20720,00 \\
\hline $\begin{array}{l}\text { ELIA NETO; NAKAHODO, } \\
1995 \text { apud ROCHA et al., } \\
\text { 2012) }\end{array}$ & 2034,89 & 60,41 & 515,25 & 51,55 & 225,64 & 356,63 & 28450,00 & 76949,76 \\
\hline
\end{tabular}

Fonte: dos autores.

A quantidade de matéria orgânica presente em um efluente é um fator de extrema importância, associada ao principal problema de poluição no meio aquático, que é a diminuição de seus teores de oxigênio dissolvido. Essa diminuição ocorre devido ao fato dos microrganismos decompositores consumirem oxigênio em seus processos de metabolização e estabilização da matéria orgânica. $A$ DBO (Demanda Bioquímica de Oxigênio) e a DQO (Demanda Química de Oxigênio) são os principais parâmetros avaliados nesse caso. Ambas medem indiretamente o teor de matéria orgânica em um efluente e indicam seu potencial poluidor. A DBO indica a quantidade de oxigênio necessária para estabilizar a matéria orgânica, através de processos bioquímicos (microrganismos), enquanto a DQO faz a quantificação, através da oxidação química, usando um forte agente oxidante (VON SPERLING, 1996). De acordo com Rocha et. al. (2012) o valor médio da DBO da vinhaça é de $16000 \mathrm{mg} \cdot \mathrm{L}^{-1}$, um valor extremamente alto se comparado a outros efluentes industriais tais como: de curtumes ( $\left.4000 \mathrm{mg} \cdot \mathrm{L}^{-1}\right)$, de fábricas de manteiga (1400 mg. $\left.\mathrm{L}^{-1}\right)$, de indústrias têxteis (1200 mg. $\left.\mathrm{L}^{-1}\right)$, de fábricas de carne (900 $\left.\mathrm{mg} \cdot \mathrm{L}^{-1}\right)$, de cervejarias $\left(600 \mathrm{mg} \cdot \mathrm{L}^{-1}\right)$, de fábricas de papel e celulose $\left(500 \mathrm{mg}^{\mathrm{L}^{-1}}\right)$ e também a esgotos domésticos (300 mg. $\left.\mathrm{L}^{-1}\right)$, o que evidencia o seu elevado potencial de degradação ambiental. Outras características desse efluente são o seu baixo pH (elevada acidez) e alta corrosividade (MUTTON et. al., 2010). Esta é devida ao valores de $\mathrm{pH}$ em torno de 4,3 e à elevada temperatura empregada na etapa em que a vinhaça é obtida, durante a produção do etanol (LAIME, 2011). Quantidades muito pequenas de metais pesados também podem ser encontradas na composição da vinhaça. Isso porque, esses são nutrientes necessários no cultivo da cana de açúcar. Ou então, são provenientes do desgaste ou corrosão ou ainda abrasão dos maquinários metálicos usados durante o processo de obtenção do etanol. Destaca-se que as quantidades presentes desses metais geralmente, estão dentro dos valores aceitáveis, não atingindo níveis de risco (MUTTON et. al., 2010).

\section{IMPACTOS AMBIENTAIS}

Na literatura muitos relatos descrevem a periculosidade da vinhaça quando descartada ou usada inadequadamente como, por exemplo, in natura, ao meio ambiente. Há diversos estudos, tais como os realizados por Lyra et. al. (2003), Manhães et. al. (2003), Paulino et. al. (2011) e Hassuda et. al. (1990) que visam identificar sua atuação na natureza e de que modo os ecossistemas, quando contaminados, são afetados. A vinhaça é uma suspensão aquosa de sólidos orgânicos e minerais, que contêm componentes do vinho, não eliminados no processo de destilação (CAMARGO et. al., 1990). Além disso, pode conter ainda vestígios de açucares e de etanol e compostos menos voláteis. Assim sendo, devido à toxicidade de alguns desses componentes, fica claro o porquê da vinhaça ser danosa quando em contato com os meios biótico e físico. Segundo Lima (2013) devida à sua elevada carga orgânica, os danos causados pelo descarte inadequado da vinhaça, à flora e fauna dos mananciais foram enormes. Em função disso, ocorreram às primeiras tentativas de enquadrá-la em uma classificação de resíduos. 
No decorrer da fermentação alcoólica é empregada a levedura Sacharomyces Cerevisiae, que apresenta como inconveniente a baixa tolerância ao etanol. Assim, no processo produtivo, a presença do etanol diminui a taxa de produção e obriga o uso de uma alta diluição do mosto para reduzir o teor alcoólico do vinho. A temperatura também influencia de maneira crucial essa tolerância da levedura. Por isso, após a destilação, ocorre a produção de grande quantidade de vinhaça por litro de álcool (MUTTON et. al., 2010). Essa quantidade apresenta uma variação considerável, mas de forma geral, as usinas mais recentes apresentam uma produção média de 7 a $10 \mathrm{~L}$ de vinhaça por litro de etanol e as mais antigas, de 10 a $15 \mathrm{~L}$ de vinhaça por litro de etanol (ROCHA et. al., 2012).

Kannan et. al. (2006) explicita que a coloração escura e a turbidez da vinhaça dificultam a penetração da luz solar, o que prejudica o ecossistema aquático no qual essa foi descartada. Como as moléculas presentes de melanoidinas, não são facilmente decompostas por tratamentos biológicos convencionais e essas geram alta DQO, torna-se mais difícil o controle do impacto ambiental gerado. Segundo Lyra et. al. (2003), a vinhaça apresenta DBO da ordem de 12.000 a 20.000 mg. L-1. A comparação dos valores de $\mathrm{DBO}$ da vinhaça e do esgoto doméstico não tratado demonstra que o impacto ambiental causado por um litro de vinhaça é o mesmo impacto gerado pelo esgoto produzido por 1,43 pessoas em um dia. Logo, de acordo Lima (2013), ao se produzir 10 litros de etanol (levando em consideração que são gerados cerca de 12 litros de vinhaça por litro de etanol produzido), a poluição ocasionada será de aproximadamente o equivalente ao esgoto gerado por 172 pessoas em um dia.

O Código Penal Brasileiro, diversas Leis Estaduais e Portarias vetam a pratica de descarte desse resíduo em leitos d'água. Especialmente, a Portaria $n^{\circ} 322$, publicada em novembro de 1978, pelo Ministério do Interior, que proíbe o lançamento direto e/ou indireto da vinhaça, em qualquer coleção hídrica, pelas destilarias. Essa também obriga as indústrias sucroalcooleiras a apresentarem projetos para implementação de sistemas que utilizem de modo racional a vinhaça e as águas residuais geradas pela fabricação do etanol ou ainda sistemas para tratamento desse resíduo (GRANATO, 2003). A vinhaça é atualmente classificada como Resíduo CLASSE IIA - NÃO INERTE, por conter concentrações de substâncias solubilizadas que excedem o máximo o permitido pelos padrões de potabilidade da água conforme o anexo $\mathrm{G}$ da norma da ABNT 10.004/2004 (ROCHA et. al., 2012).

Usualmente, a vinhaça é empregada na fertirrigação de canaviais. Apesar de esse uso diminuir a quantidade de resíduo disponível, apresenta elevado potencial poluidor. Pois, nesse caso, não são atendidos todos os parâmetros exigidos pelo CONAMA para rios CLASSE 2. Essa chega até os lençóis freáticos, afetando-os em taxas da ordem de $300 \mathrm{~m}^{3}$.ha-1 (LYRA et.al., 2003). Alguns experimentos envolvendo a aplicação de vinhaça a longo prazo, no solo, demonstraram que há variação do comportamento de acumulação e, ou, percolação do potássio (K). Todas as áreas estudadas apresentaram teores muito elevados, inclusive em profundidade, chegando até o lençol freático. Verificou-se que o

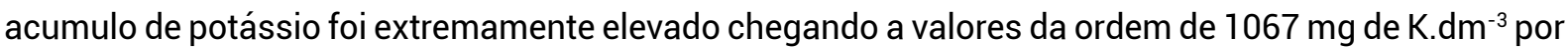

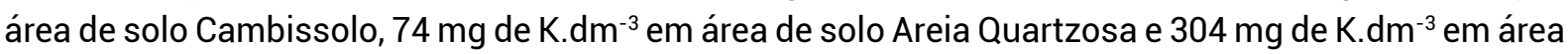
de solo Gley Húmico (MANHÃES et.al., 2003). A aplicação prolongada da vinhaça causa a diminuição do $\mathrm{pH}$, ou seja ocorre um aumento na acidez do meio. Esse fato foi explicitado pelo estudo de Paulino et. al. (2011), o qual tratou áreas de cultivo de cana de açúcar, com aplicações sucessivas de vinhaça, durante 1, 2, 3, 4, 12 e 20 anos, respectivamente, e uma área de testemunha (controle) sem aplicação. Os resultados obtidos evidenciam que houve uma diminuição no $\mathrm{pH}$ do solo ao longo dos anos de aplicação da vinhaça. Essa aplicação excessiva provoca efeitos negativos no solo, como a salinização, que impede o desenvolvimento das plantas (ROCHA et. al., 2012). Miranda (2009) argumenta que pode ocorrer também o desbalanceamento catiônico do solo, causando uma redução na sua produção vegetal. Com isso, Lima (2013), explicita que o emprego da fertirrigação deve ser realizado com cautela, de forma fracionada e controlada. Deve-se salientar que volumes elevados de vinhaça, não utilizados na fertirrigação, são armazenados nas chamadas "áreas de sacrifício". Hassuda et. al. (1990) estudou 
os impactos causados pela infiltração de vinhaça no aquífero Bauru. Ele verificou que alguns valores dos parâmetros do padrão de potabilidade da água para consumo humano mostraram-se acima do permitido pela legislação, tais como o nitrogênio amoniacal, encontrado em valores entre $>0,005 \mathrm{e}$ $9,8 \mathrm{mg} \cdot \mathrm{L}^{-1}$, o magnésio, entre $>12,0$ e $210,0 \mathrm{mg} \cdot \mathrm{L}^{-1}$, o alumínio, entre $>0,02$ e $23,0 \mathrm{mg} \cdot \mathrm{L}^{-1}$, o ferro, entre $>0,005$ e $60,0 \mathrm{mg} \cdot \mathrm{L}^{-1}$, o manganês, entre 5,0 e $60,0 \mathrm{mg} . \mathrm{L}^{-1}$, e o cloreto, entre 4,0 e $640 \mathrm{mg} \cdot \mathrm{L}^{-1}$. Dessa forma, foram evidenciados os impactos que a infiltração de vinhaça pode causar a água subterrânea, tornando-a imprópria para consumo humano, quando aplicada de forma exacerbada. Tal estudo confirmou a capacidade de infiltração da vinhaça no solo e os danos que as áreas de sacrifício podem causar ao meio ambiente.

\section{CONCLUSÕES}

A vinhaça é um efluente proveniente da indústria sucroalcooleira gerado em grandes volumes. Esse apresenta elevadas concentrações de materiais orgânicos e inorgânicos. Concomitante, sua corrosividade, $\mathrm{pH}$ baixo (ácido) e elevadas DBO e DQO garantem a esse resíduo um grande potencial de danos a fauna e flora, bem como ao solo e lençóis freáticos.

A fertirrigação, como fonte usual desse material, apresenta uma limitação quanto à dosagem máxima a ser usada, desse resíduo, no solo. 0 uso de uma dosagem acima desse limite causa danos à natureza e, ainda assim, um grande volume da vinhaça mantém-se sem destinação. Dessa forma, verifica-se que são fundamentais pesquisas voltadas a sanar ou minimizar os efeitos e danos ambientais, bem como o desenvolvimento de aplicações empregando-se esse efluente. 


\section{REFERÊNCIAS}

ANDRADE, E. T.; CARVALHO, S. R. G.; SOUZA, L. F. Programa do Proálcool e o etanol no Brasil. Engevista, v. 11, n. 2, p. 127-136, 2009.

BARROS, R. P.; VIÉGAS P. R. A.; SILVA T. L.; SOUZA R. M.; BARBOSA L.; VIÉGAS R. A.; BARRETTO M. C. V.; MELO A. S. Alterações em atributos químicos de solo cultivado com cana de açúcar e adição de vinhaça. Pesquisa Agropecuária Tropical, v. 40, n. 3, p. 341-346, 2010.

BRITO, F. L.; ROLIM M. M. Comportamento do efluente e do solo fertirrigado com vinhaça. Agropecuária Técnica, v. 26, n. 1, p. 60-67, 2005.

CAMARGO, C.A., USHIMA, A. H., RIBEIRO, A. M. M. Conservação de Energia na Indústria do Açúcar e do Álcool: Manual de Recomendações. 1 ed. São Paulo: Instituto de Pesquisas Tecnológicas, 1990, 796 p.

CHANDRA, R.; BHARAGAVA, R. N.; RAI, V. Melanoidins as major colourant in sugarcane molasses based distillery effluent and its degradation. Bioresource Technology, v. 99, n. 11, p. 4648-4660, 2008.

CONAB. Acompanhamento de safra brasileira: cana-de-açúcar, terceiro levantamento, Dezembro 2015. Companhia Nacional de Abastecimento, Brasília, v.2, n.3, p. 1-65, 2015.

GRANATO, E. F. Geração de energia através da biodigestão anaeróbica da vinhaça. Dissertação (Mestrado em Engenharia Industrial) - Universidade Estadual Paulista, Campus de Bauru, Bauru, 2003, 139 p.

HASSUDA, S; ROBOUÇAS, A. C.; CUNHA, R. C. A. Aspectos qualitativos da infiltração da vinhaça de cana no aquífero Bauru. Revista IG, São Paulo, v. 11, n. 2, p. 5-20, 1990.

KANNAN, N.; KARTHIKEYAN, G.; TAMILSELVAN, N. Comparison of treatment potential of electrocoagulation of distillery effluent with and without activated Areca catechu nut carbon. Journal of Hazardous Materials, v. 137, n. 3, p. 1803-1809, 2006.

LAIME, E. M. O.; FERNANDES, P. D.; OLIVEIRA, D. C. S.; FREIRE, E. A. Possibilidades tecnológicas para a destinação da vinhaça: uma revisão. Revista Trópica: Ciências Agrárias e Biológicas, Chapadinha, v. 5, n. 3, p. 16-29, 2011.

LIMA, H. H. S. Tratamento físico-químico da vinhaça por coagulação e adsorção em carvão ativado do bagaço da cana de açúcar. Dissertação (Mestrado em Engenharia Urbana e Ambiental) - Centro de Tecnologia, Universidade Federal da Paraíba, João Pessoa, 2013, 84 p.

LUDOVICE, M. T. F. Estudo do efeito poluente da vinhaça infiltrada em canal condutor de terra sobre o lençol freático. Dissertação (Mestrado em Engenharia Civil) - Universidade Estadual de Campinas, Campinas, 1997, $143 \mathrm{p}$.

LYRA, M. R. C. C.; ROLIM, M. M.; SILVA, J. A. A. D. Topossequência de solos fertigados com vinhaça: contribuição para a qualidade das águas do lençol freático. Revista Brasileira de Engenharia Agrícola e Ambiental, Campina Grande, v.7, n.3, p. 525-532, 2003.

MANHÃES, M. S.; SOUZA, D.; BERTO, P. N. A. Acúmulo de potássio em solos de áreas canavieiras fertirrigadas no norte fluminense. Agronomia, v.37, n.1, p. 64-68, 2003. 
MIRANDA, T. L. Relações entre atributos físicos e biológicos do solo após operações de colheita e aplicação de vinhaça em cana-de-açúcar. Dissertação (Mestrado) -Universidade Federal Rural de Pernambuco, Recife, 2009, 81 p.

MOHANA, S.; DESAI, C.; MADAMWAR, D. Biodegradation and decolourization of anaerobically treated distillery spent wash by a novel bacterial consortium. Bioresource Technology, v. 98, n. 2, p. 333-339, 2006.

MUTTON, M. A.; ROSSETTO, R.; MUTTON, M. J. R. Utilização agrícola da vinhaça. In: CORTEZ, L. A. B. Bioetanol de cana-de-açúcar: P\&D para produtividade e sustentabilidade. São Paulo: Blucher, 2010. Capítulo 10. p. 423-440.

PAULINO, J.; ZOLIN, C. A.; BERTONHA, A.; FREITAS, P. S. L.; FOLEGATTI, M. V. Estudo exploratório do uso da vinhaça ao longo do tempo. II. Características da cana-de-açúcar. Revista Brasileira de Engenharia Agrícola e Ambiental, Campina Grande, v.15, n.3, p. 244-249, 2011.

ROCHA, M. H.; NETO, A. E.; SALOMON, K. R.; LORA, E. E. S.; VENTURINI, O. J.; OLMO, O. A.; RAMBLA, M. A. O. Resíduos da produção de biocombustíveis: vinhaça e glicerina. In: LORA, E. E. S.; VENTURINI, O. J. Biocombustíveis: volume 2. Rio de Janeiro: Interciência, 2012. Capítulo 12. p. 691-809.

SEIXAS, F. L.; GIMENES, M. L.; MACHADO N. R. C. F. Tratamento da vinhaça por adsorção em carvão de bagaço de cana de açúcar. Química Nova, v. 39, n. 2, p. 172-179, 2016.

SILVA, A. Vinhaça concentrada de cana-de-açúcar. monitoramento das propriedades químicas do solo e mineralização líquida de nitrogênio. Tese (Doutorado em Ciências) - Centro de Energia Nuclear na Agricultura, Universidade de São Paulo, Piracicaba, 2012, 109 p.

SILVA, M. A. S.; GRIEBELER, N. P.; BORGES, L. C. Uso de vinhaça e impactos nas propriedades do solo e lençol freático. Revista Brasileira de Engenharia Agrícola e Ambiental, Campina Grande, v. 11, n.1, p. 108-114, 2007.

VON SPERLING, M. Introdução à qualidade das águas e ao tratamento de esgotos. 3 ed. Belo Horizonte: Editora UFMG, 1996, $243 \mathrm{p}$. 